\title{
Temporal trends in tetanus incidence and lethality in Brazil: analysis of the national database from 2009 to 2018
}

\author{
Larissa Chaves de Carvalho ${ }^{10}$, Consuelo Penha Castro Marques ${ }^{1}{ }^{(0)}$, \\ Vandilson Pinheiro Rodrigues ${ }^{2 *}$
}

\begin{abstract}
SUMMARY
OBJECTIVE: This study aimed to analyze the epidemiological and hospital characteristics of cases and deaths due to accidental tetanus in Brazil. METHODS: A time-series study with secondary data extracted from the Department of Informatics of the Brazilian Unified Health System. The time series were evaluated by linear regression parameters, considering a significance level of $1 \%$.

RESULTS: A total of 2,772 cases were reported between 2009-2018. Predominant cases were men and aged between 40-59 years old, with incomplete $1 \mathrm{st}-4$ th grade. The lethality rate was found to be predominant in women, whites, illiterates, and those who aged above 80 years. The overall lethality was $32.5 \%$. The incidence rate reduced from 1.6 in 2009 to 0.95 per million inhabitants in 2018, but lethality increased from $30.77-40.70 \%$. The highest rate of incidence and lethality occurred in the elderly people and in the northern region. CONCLUSION: The high cost and lethality of tetanus configure it as a public health problem. The demonstration of the epidemiology of patients who most evolve to death can help to contribute to a reduction in lethality, which shows an increase in the analysis period. Finally, special attention should be given to the elderly people and those living in the northern region.

KEYWORDS: Tetanus. Incidence. Epidemiology. Brazil.
\end{abstract}

\section{INTRODUCTION}

Tetanus is an infectious and noncontagious disease caused by the anaerobic gram-positive bacteria. Clostridium tetani can enter the body through a continuity solution caused by injury in the skin or mucosa ${ }^{1}$. Inside the host, the bacterium finds favorable conditions to multiply, take on a filamentous form, and produce neurotoxins ${ }^{2}$. Tetanospamin neurotoxin can act on the nerve terminals, resulting in the failure to inhibit motor reflexes, and generalized contractions of the agonist and antagonist muscles, causing tetanic spasms $s^{3,4}$.

Treatment includes debridement of focus, antibiotic therapy, immunization, neuromuscular blockers, and early tracheostomy ${ }^{5}$.
The high lethality rate and complications of this disease occur mainly due to the dysfunction of the respiratory muscles ${ }^{6}$. All these factors make the treatment of tetanus more complex and expensive for the health system ${ }^{7}$.

Despite its acute and severe behavior, tetanus is an immune preventable disease. According to the Basic Vaccination Calendar adopted by the Ministry of Health of Brazil, tetanus immunization, the pentavalent vaccine, should be administered at 2 , 4 , and 6 months, with boosters at 12-15 months and 4 years as diphtheria-tetanus-pertussis (DTP) vaccine, and between 10-19 years old as diphtheria and tetanus (DT) vaccine, and needs reinforcement every 5 or 10 years if at risk or during

\footnotetext{
'Universidade Federal do Maranhão, Departamento de Medicina - São Luís (MA), Brazil.

2Universidade Federal do Maranhão, Departamento de Morfologia - São Luís (MA), Brazil.

*Corresponding author: vandilson.rodrigues@ufma.br

Conflicts of interest: the authors declare there is no conflicts of interest. Funding: This work was financially supported by the Research Support Foundation of Maranhão State (FAPEMA) and the Coordenação de Aperfeiçoamento de Pessoal de Nível Superior (CAPES) [Finance Code 001]. Received on September 16, 2021. Accepted on September 17, 2021.
} 
pregnancy ${ }^{8}$. In addition to scheduled vaccination, an emergency prophylactic dose after exposure to risky situations can reduce by approximately four times the patient's chance of progressing to death ${ }^{9,10}$.

In 2020, global tetanus incidence data estimated the occurrence of 11,763 new cases, with the European continent having the lowest incidence and the African continent having the highest incidence, followed by South-East Asia ${ }^{11}$. In Brazil, between 1982 and 2006, tetanus cases reduced by more than $80 \%$, from $1.8-0.22$ cases per 100,000 inhabitants. However, the lethality rate did not reduce ${ }^{12}$. This situation is especially worrisome since tetanus is an immune-preventable disease. For this reason, more efficient health measures are desirable, with an approach at the collective level and with interventions at wide population coverage.

Therefore, considering the high lethality of tetanus, the high cost of treating this condition in addition to the scarcity of recent studies that address the epidemiological, hospital, and mortality characteristics of tetanus in Brazil, the objective of the present study was to investigate the epidemiological profile of cases reported and deaths from tetanus, by Brazilian macro-regions from 2009-2018.

\section{METHODS}

A time-series study was conducted with secondary data extracted from the Department of Information of the Brazilian Unified Health System (DATASUS). The variables collected included information on the epidemiological profile and hospital data on cases and deaths from tetanus reported in Brazil from 20092018. Analyses were carried out at the national geographical levels, the Brazilian macro-regions (North, Northeast, Midwest, Southeast, and South), and the Federative Unit of Brazil.

Secondary data were extracted from the Information System for Notifiable Diseases (SINAN) and the Hospital Information System of the Unified Health System (SIH/SUS). In addition, population data were obtained through census data and estimates collected on the platform of the Brazilian Institute of Geography and Statistics (IBGE).

The following variables were collected: educational status, sex, race, age group, type of disease, the evolution of the disease, number of hospitalizations, average hospitalization value, the average length of stay, and deaths during hospitalization. Notified cases of neonatal tetanus were excluded. The average amount spent on hospitalization was obtained by the total value of hospitalizations divided by the number of hospitalizations. The average length of stay was obtained by the sum of all days spent divided by the number of hospitalizations.

The lethality rate was calculated using the ratio between the number of cases with evolution to death and the total number of reported cases of tetanus in the same region and year. The tetanus incidence rate was calculated by macro-region and age group.

Statistical analysis used GraphPad Prism version 9.1 (GraphPad Software Inc., San Diego, CA, USA). Descriptive statistics included measures of absolute and relative frequency. Time series were evaluated using parameters estimated through linear regression. The level of significance adopted was $1 \%$.

\section{RESULTS}

In Brazil, 2,772 cases of tetanus were reported from 2009-2018 and were distributed as follows: 918 in the Northeast (NE), 625 in the Southeast (SE), 545 in the South (S), 361 in the North (N), and 323 in the Midwest (CO). The three states with the highest numbers of tetanus cases were Minas Gerais, Rio Grande do Sul, and Sáo Paulo.

The reported cases of tetanus in Brazil reduced during 10 years of analysis ( 325 cases in 2009 , declining to 199 cases in 2018). An important finding in the analysis of the time series was the significant reduction in cases in the $\mathrm{NE}$ over time $(-50 \% ; \beta=-6.9 ; p=0.003)$. The other regions showed stable behavior in the period (Figure 1A).

The overall incidence in Brazil decreased from 1.7 per million inhabitants in 2009 to 0.95 per million inhabitants in 2018. The greatest reduction was in the Midwest region, from 3.3 per million inhabitants in 2009 to 0.75 per million inhabitants in 2018 (Figure 1B). In all these years, the Southeast region had the lowest incidence, and the Northeast $(\mathrm{p}=0.001)$ showed a significant decrease.

In the analysis of the time series, there was an increase in lethality by tetanus in Brazil, being 30.77\% in 2009 and $40.70 \%$ in 2018 , with emphasis on the increase of the lethality observed in the Northeast region, with $25.41 \%$ lethality in 2009 and $47.54 \%$ in 2018 ( $\mathrm{p}=0.007$ ). The highest lethality rate was in the North region at $48.6 \%$ in 2016 and the lowest in the Midwest at $4.5 \%$ in 2017 (Figure 1C). When the incidence rate was analyzed by age group, the highest rate occurred in those who aged $\geq 60$ years (Figure 1D).

The highest proportion of cases occurred in individuals with low schooling. The male gender predominated in the approximate proportion of six men for each woman $(6: 1)$. The most frequent age group was 40-59 years (Table 1).

Due to the high lethality of tetanus, this study further analyzed the epidemiological profile associated with death. The lethality rate was higher among illiterates, whites, females, and those who aged above 65 years (Table 1).

There were 1,993 admissions to the hospital due to tetanus. The average value of each hospitalization was $\mathrm{R} \$ 5,522.61$, with an average stay of 17 days and a lethality rate of $19.5 \%$ during hospitalization. Table 2 shows distribution according to region. 

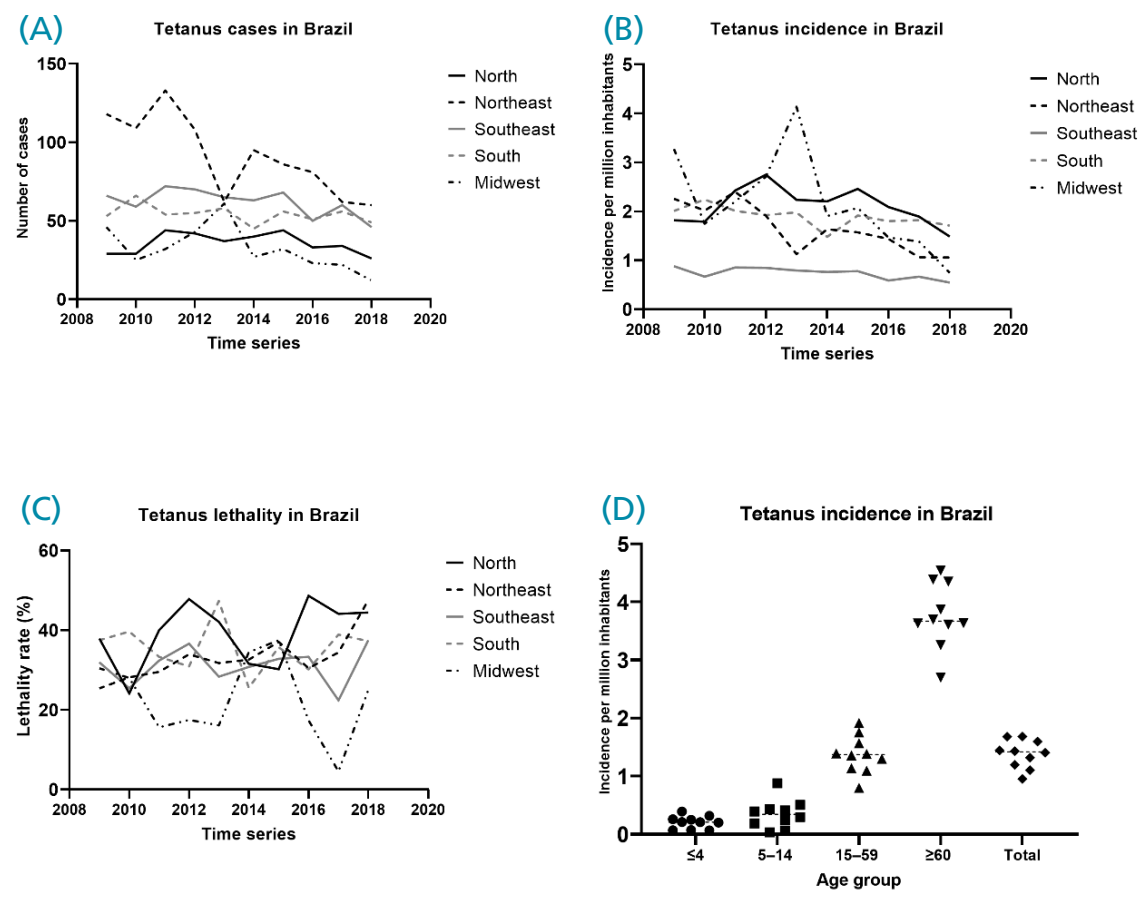

Figure 1. (A) Time series of tetanus cases; (B) tetanus incidence rate per million inhabitants; (C) tetanus lethality rate in Brazil according to macro-region; (D) and tetanus incidence rate in Brazil according to age group.

\section{DISCUSSION}

The main findings of the present study show that reported cases of tetanus in Brazil from 2009-2018 predominated in individuals from the 1st-4th grade of elementary school and in males in the approximate proportion of $6: 1$ when compared with females. The age group most affected was 40-59 years. Our findings are in agreement with other studies carried out in Brazil with other time frames ${ }^{13}$.

The higher prevalence in men can be explained by their greater exposure to work activities, in addition to the routine vaccination of pregnant women in prenatal care ${ }^{14}$. The predominance in adults and the elderly people emphasizes that strategies are also needed to update the vaccination calendar of this group, as well as that of the population with low education, and not only in maternal and child vaccinations ${ }^{15}$.

The incidence rate for Brazil in 2009 when compared with that of the USA (0.1 per million inhabitants in 2008) was approximately 10 times higher ${ }^{16}$. Some explanations for this finding are that less than $50 \%$ of people with acute injuries seek health care in Brazil and some patients fail to receive post-exposure tetanus prophylaxis due to the harmless appearance of some injuries ${ }^{17}$. According to the European Center for Disease Prevention and Control, the incidence rate in Europe in 2017 (0.2 per million inhabitants) was also lower than in Brazil ${ }^{18}$.
Despite the still high rate, our study, as well as other studies, showed a reduction from 1.7 per million inhabitants to 0.95 per million inhabitants, from 2009-2018, the largest reduction in the Midwest region. This reduction may be due to greater access to health services, better vaccination coverage, and greater educational and socioeconomic development ${ }^{14,15}$.

The highest rate of tetanus incidence in individuals aged $\geq 60$ years is in line with national and international literature ${ }^{15}$. This greater risk is due to inadequate vaccination, as the vaccine is sufficiently immunogenic in the elderly people ${ }^{16}$. Furthermore, over the years, psychomotor capacity and perception of space have decreased, resulting in the elderly people more susceptible to accidents ${ }^{13}$.

Great emphasis has been placed on maternal and child vaccination. However, when establishing strategies that focused on certain groups, managers take the risk of neglecting others. Therefore, vaccination campaigns regardless of sex and age, training of health professionals, and observation in each contact as a timely way of immunization are necessary ${ }^{19}$. In addition to vaccination strategies, it is essential to pay attention not only to the risk of tetanus in acute injuries but also to how protocols are formulated for managing chronic injuries that are common in the elderly people ${ }^{17}$. 
Table 1. Descriptive analysis of tetanus cases and lethality rate reported in Brazil (2009-2018).

\begin{tabular}{|c|c|c|c|c|}
\hline & \multirow{2}{*}{ Categories } & \multicolumn{2}{|c|}{ Cases } & \multirow{2}{*}{$\begin{array}{c}\text { Lethality rate } \\
\%\end{array}$} \\
\hline & & $n$ & $\%$ & \\
\hline \multirow{11}{*}{ Educational level (in years) } & Illiterate & 141 & 5.09 & 42.55 \\
\hline & $<$ Grade 4 (elementary school) & 418 & 15.08 & 33.73 \\
\hline & Grade 4 (elementary school) & 160 & 5.77 & 31.25 \\
\hline & 5-8 (elementary school) & 289 & 10.43 & 23.53 \\
\hline & Complete elementary school & 169 & 6.10 & 33.73 \\
\hline & Incomplete high school & 83 & 2.99 & 25.30 \\
\hline & Complete high school & 135 & 4.87 & 25.93 \\
\hline & Incomplete graduate level & 12 & 0.43 & 8.33 \\
\hline & Complete graduate level & 26 & 0.94 & 30.77 \\
\hline & Not applicable & 42 & 1.52 & - \\
\hline & No data & 1,297 & 46.79 & - \\
\hline \multirow{6}{*}{ Color/race } & White & 878 & 31.67 & 34.97 \\
\hline & Black & 225 & 8.12 & 32.00 \\
\hline & Yellow & 28 & 1.01 & 14.29 \\
\hline & Brown & 1,417 & 51.12 & 31.97 \\
\hline & Indigenous & 8 & 0.29 & 25.00 \\
\hline & No data & 216 & 7.79 & - \\
\hline \multirow{2}{*}{ Sex } & Male & 2,360 & 85.14 & 31.02 \\
\hline & Female & 412 & 14.86 & 41.02 \\
\hline \multirow{17}{*}{ Age group (years) } & $<1$ & 18 & 0.65 & 27.78 \\
\hline & $01-04$ & 13 & 0.47 & 30.77 \\
\hline & 05-09 & 38 & 1.37 & 18.42 \\
\hline & $10-14$ & 77 & 2.78 & 24.68 \\
\hline & $15-19$ & 99 & 3.57 & 11.11 \\
\hline & $20-39$ & 576 & 20.78 & 22.92 \\
\hline & $40-59$ & 1,106 & 39.90 & 31.74 \\
\hline & $60-64$ & 255 & 9.20 & 34.51 \\
\hline & $65-69$ & 220 & 7.94 & 45.00 \\
\hline & $70-79$ & 277 & 9.99 & 47.29 \\
\hline & 80 or above & 93 & 3.35 & 58.06 \\
\hline & 1st trimester & 1 & 0.04 & 0.00 \\
\hline & 2nd trimester & 2 & 0.07 & 100.00 \\
\hline & Without gestational age data & 1 & 0.04 & 100.00 \\
\hline & No & 263 & 9.49 & 39.92 \\
\hline & Not applicable & 2,486 & 89.68 & 31.62 \\
\hline & No data & 19 & 0.69 & - \\
\hline \multirow{3}{*}{ Autochthone } & Yes & 2,261 & 81.57 & 33.83 \\
\hline & No & 219 & 7.90 & 31.96 \\
\hline & No data & 292 & 10.53 & - \\
\hline \multirow{4}{*}{ Case follow-up } & Recovery & 1,470 & 53.03 & - \\
\hline & Death by tetanus & 901 & 32.50 & - \\
\hline & Death by another cause & 61 & 2.20 & - \\
\hline & No data & 340 & 12.27 & - \\
\hline
\end{tabular}


Table 2. Tetanus data from Brazilian Unified Health System (2009-2018).

\begin{tabular}{l|c|c|c} 
Macro-region & $\begin{array}{c}\text { Hospital } \\
\text { admission }\end{array}$ & $\begin{array}{c}\text { Average } \\
\text { cost (in R\$) }\end{array}$ & $\begin{array}{c}\text { Average } \\
\text { stay } \\
\text { (in days) }\end{array}$ \\
\hline North & 313 & $3,468.32$ & 12.7 \\
\hline Northeast & 637 & $4,688.28$ & 18.1 \\
\hline Southeast & 444 & $7,348.89$ & 19 \\
\hline South & 398 & $6,572.74$ & 16.9 \\
\hline Midwest & 141 & $5,137.1$ & 14.9 \\
\hline Total & 1,933 & $5,522.61$ & 17 \\
\hline
\end{tabular}

The lethality of tetanus in Brazil was 32.5\%, similar to Nigeria but much higher than that in developed countries, such as the USA $(13.2 \%)^{16}$ and Japan $(6.8 \%)^{20}$. The outcome of tetanus cases is primarily related to the quality of care, early diagnosis, and treatment ${ }^{21,22}$. A systematic review of 27 studies involving 3,043 patients showed that the mortality rate in African patients was $43 \%$. This high lethality was because mechanical ventilation is not accessible in many medical facilities ${ }^{23}$.

In the present study, the lethality rate was higher in illiterates, whites, females, and those who aged above 65 years old. Evidence has demonstrated a greater chance of progressing to death in female patients (3.46 times more than in men) and in those who aged above 60 years $^{19}$.

The average value of each hospitalization was $\mathrm{R} \$ 5,522.61$ (Brazilian real BRL), sufficient to purchase about 12,500 vaccines, considering that the value of one dose of the DT vaccine (adult double) was approximately $\mathrm{R} \$ 0.41^{24}$. This reinforces the cost-benefit of vaccination policies, regardless of age and gender.

Studies have shown the high cost of treatment and support for tetanus. Some developed countries such as the United Kingdom have used the Tetanus Quick Stick (TQS) test, a rapid test to assess serological status in individuals with suspected lesions, to avoid unnecessary expenses with prophylaxis, since less than $50 \%$ of patients remember about their vaccination ${ }^{25}$. However, it is necessary to assess the cost-benefit in Brazil.

The wide variation between mortality during hospitalization, length of stay, and costs in Brazilian regions suggest intense variability within the same country in the management of patients with tetanus. Health professionals' knowledge of post-injury prophylaxis and tetanus management is essential. Thus, it is necessary to train and update professionals who work in a hospital environment ${ }^{24}$. These findings could help researchers, health workers, and health system administrators in planning more effective intervention strategies to reduce tetanus incidence across diverse Brazilian regions. In addition, the findings indicate that new policies must be planned considering specific strategies for the most vulnerable population groups.

\section{CONCLUSION}

The study findings showed that the tetanus incidence rate in Brazil is declining. However, special attention should be paid to the elderly people, who have the highest incidence rate and the highest lethality. Greater attention is also needed in the northern region, due to the higher lethality of tetanus as well as the predominance of the highest incidence rate in Brazil, in most years.

\section{AUTHORS" CONTRIBUTIONS}

LCC: Conceptualization, Data curation, Formal Analysis, Writing - original draft. CPCM: Conceptualization, Investigation, Writing - review \& editing. VPR: Project administration, Data curation, Formal analysis, Validation, Writing - review \& editing.

\section{REFERENCES}

1. Hassel B. Tetanus: pathophysiology, treatment, and the possibility of using botulinum toxin against tetanus-induced rigidity and spasms. Toxins (Basel). 2013;5(1):73-83. https:// doi.org/10.3390/toxins5010073

2. Afshar M, Raju M, Ansell D, Bleck TP. Narrative review: tetanus-a health threat after natural disasters in developing countries. Ann Int Med. 2011;154(5):329-35. https://doi. org/10.7326/0003-4819-154-5-201103010-00007

3. Thwaites CL, Loan HT. Eradication of tetanus. Br Med Bull. 2015;116(1):69-77. https://doi.org/10.1093/bmb/ldv044
4. Driessche A, Janssens B, Coppens Y, Bachmann C, Donck J. Tetanus: a diagnostic challenge in the Western world. Acta Clin Belg. 2013;68(6):416-20. https://doi.org/10.2143/ACB.3336

5. Neves FF, Faiolla RC, Napoli EM, Lima GM, Muniz RZ, Pazin-Filho A. Perfil clínico-epidemiológico dos casos de tétano acidental ocorridos em Ribeirão Preto, Estado de São Paulo, no período de 1990 a 2009. Rev Soc Bras Med Trop. 2011;44(4):481-5. https://doi.org/10.7326/0003-4819-154-5-201103010-00007

6. Bunch TJ, Thalji MK, Pellikka PA, Aksamit TR. Respiratory failure in tetanus: case report and review of a 25 -year experience. Chest. 2002;122(4):1488-92. https://doi.org/10.1378/chest.122.4.1488 
7. Feijão $A R$, Brito DM, Peres DA, Galvão MT. Tétano acidental no Estado do Ceará, entre 2002 e 2005 [Accidental tetanus in the State of Ceará, between 2002 and 2005]. Rev Soc Bras Med Trop. 2007;40(4):426-30. https://doi.org/10.1590/ S0037-86822007000400011

8. Brasil. Ministério da Saúde. Secretaria de Vigilância em Saúde. Departamento de Vigilância Epidemiológica. Programa Nacional de Imunizações (PNI): 40 anos. [Internet]. Brasília: Ministério da Saúde; 2013. [cited on Jun 20, 2020]. Available from: http://bvsms.saude.gov.br/bvs/publicacoes/programa_ nacional_imunizacoes_pni40.pdf

9. Scott T. Point-of-care tetanus immunoassay: An audit of unscheduled tetanus prophylaxis. Int J Orthop Trauma Nurs. 2012;16(2):97-103. https://doi.org/10.1016/j. ijotn.2011.06.005

10. Finkelstein $P$, Teisch L, Allen CJ, Ruiz G. Tetanus: a potential public health threat in times of disaster. Prehosp Disaster Med. 2017;32(3):339-42. https://doi.org/10.1017/ S1049023X17000012

11. World Health Organization. Immunization surveillance, assessment and monitoring [Internet]. Genebra: World Health Organization; 2020. [cited on Jun 20, 2020]. Available from: http://www.who.int/immunization_monitoring/diseases/ tetanus/en/index.html

12. Santos SDSD, Barreto SM, Ho YL. Lethality and osteomuscular and cardiovascular complications in tetanus. Rev Bras Ter Int. 2011;23(4):434-41. https://doi.org/10.1590/S0103$507 \times 2011000400007$

13. Pereira AP, Nunes JRV, Silva ITC, Andrade CPPD, Araújo HVS, Xavier BLQ, et al. An epidemiological profile of accidental tetanus cases in a referral hospital, 2007-2013. Int Arch Med. 2017;10:1-7. https://doi.org/10.3823/2405

14. Gouveia PA, Silva CE, Miranda Filho DB, Bernardino SN, Escarião $A G$, Ximenes RA. Tendência temporal do tétano acidental no período de 1981 a 2004 em Pernambuco com avaliação do impacto da assistência em unidade de terapia intensiva sobre a letalidade. Rev Soc Bras Med Trop. 2009;42(1):54-7. https:// doi.org/10.1590/S0037-86822009000100011

15. Weinberger $B$. Adult vaccination against tetanus and diphtheria: the European perspective. Clin Exp Immunol. 2017;187(1):93-9. https://doi.org/10.1111/cei.12822
16. Centers for Disease Control and Prevention (CDC). Tetanus surveillance - United States, 2001-2008. MMWR Morb Mortal Wkly Rep. 2011;60(12):365-9. PMID: 21451446

17. Farnworth E, Roberts A, Rangaraj A, Minhas U, Holloway $S$, Harding K. Tetanus in patients with chronic wounds are we aware? Int Wound J. 2012;9(1):93-9. https://doi. org/10.1111/j.1742-481X.2011.00850.x

18. European Centre for Disease Prevention and Control. Tetanus. In: ECDC. Annual epidemiological report for 2017 [Internet]. Stockholm: ECDC; 2019. [cited on Jun 20, 2020]. Available from: https://www.ecdc.europa.eu/sites/default/files/documents/ tetanus-annual-epidemiological-report-2017_0.pdf

19. Beltrão RA, Pinho $C M$, Quirino EMB, Araújo ACM, Araújo SLM, Silva ABS, et al. Incidence and factors associated with death for tetanus in adults. Int Arch Med. 2020;13:1-10. https://doi.org/10.3823/2629

20. Nakajima M, Aso S, Matsui H, Fushimi K, Yasunaga H. Clinical features and outcomes of tetanus: analysis using a National Inpatient Database in Japan. J Crit Care. 2018;44:388-91. https://doi.org/10.1016/j.jcrc.2017.12.025

21. Kyu HH, Mumford JE, Stanaway JD, Barber RM, Hancock JR, Vos T, et al. Mortality from tetanus between 1990 and 2015: findings from the global burden of disease study 2015. BMC Public Health. 2017;17(1):179. https://doi.org/10.1186/s12889-017-4111-4

22. Slifka AM, Park B, Gao L, Slifka MK. Incidence of tetanus and diphtheria in relation to adult vaccination schedules. Clin Infect Dis. 2021;72(2):285-92. https://doi.org/10.1093/cid/ciaa017

23. Woldeamanuel YW, Andemeskel AT, Kyei K, Woldeamanuel MW, Woldeamanuel W. Case fatality of adult tetanus in Africa: systematic review and meta-analysis. J Neurol Sci. 2016;368:292-9. https://doi.org/10.1016/j.jns.2016.07.025

24. Ministério da Saúde. Situação epidemiológica do tétano acidental no Brasil, 2007-2016. Boletim Epidemiológico [Internet]. Brasília: Secretaria de Vigilância em Saúde. 2018 [cited on Jun 20 2020];49(25):1-15. Available from: http:// portalarquivos2.saude.gov.br/images/pdf/2018/junho/11/2017041-Tetano-publicacao.pdf

25. Martín-Casquero T, Ruescas-Escolano E, Tuells J. Use of the tetanus quick stick (TQS) test in the emergency services. Med Clin (Barc). 2019;153(10):394-401. https://doi.org/10.1016/j. medcli.2019.06.004 